\title{
SINGLE VENDOR-BUYER MODEL WITH DETERMINISTIC DEMAND, STOCHASTIC LEAD TIME AND MULTI- QUALITY DEGRADATION
}

By

Sepehr Habibollahi, B.Sc., University of Tabriz, 2014

A MRP presented to Ryerson University in partial

fulfillment of the requirements for the degree of

Master of Engineering

in the program of

Mechanical and Industrial Engineering

Toronto, Ontario, Canada, 2016

(C) Sepehr Habibollahi 2016 


\section{AUTHOR'S DECLARATION FOR ELECTRONIC SUBMISSION OF A MRP}

I hereby declare that I am the sole author of this MRP. This is a true copy of the MRP, including any required final version, as accepted by my examiners.

I authorize Ryerson University to lend this MRP to other institutions or individuals for the purpose of scholarly research.

I further authorize Ryerson University to reproduce this MRP by photocopying or by other means, in total or in part, at the request of other institutions or individuals for the purpose of scholarly research.

I understand that my MRP may be made electronically available to the public 


\begin{abstract}
ABSTARCT
SINGLE VENDOR-BUYER MODEL WITH DETERMINISTIC DEMAND, STOCHASTIC LEAD TIME AND MULTIQUALITY DEGRADATION

\author{
Sepehr Habibollahi \\ Master of Engineering
}

Mechanical and Industrial Engineering, 2016

Ryerson University, Toronto, ON, M5B 2K3, CANADA
\end{abstract}

This report examines the supply chain strategies for a specific perishable product, or fresh produce and uses green beans as an example. The quality of the products which are in direct correlation with the value of the product are put into the supply chain model, this type of model is also known as "cold chain". This report in addition to recent researches in cold chain, looks into multi aspect quality degradation and a stochastic lead time from warehouse to retailer. This model developed creates greater insight into the supply chain strategies of such products. 


\section{Acknowledgements}

I would like to thank Dr. Mohamed Wahab Mohamed Ismail for his help and time in which he dedicated to me in order to finish this project, specifically for the time he put meeting with me at such late times of the day because of my time constraints. 


\section{Table of Contents}

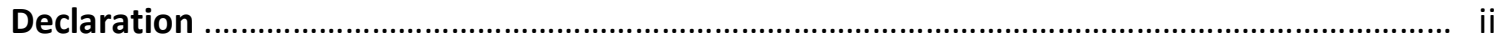

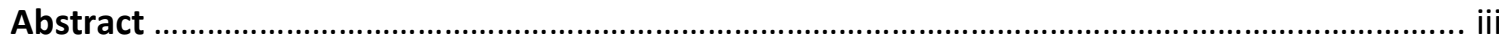

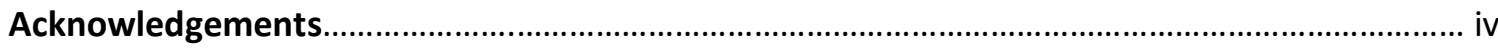

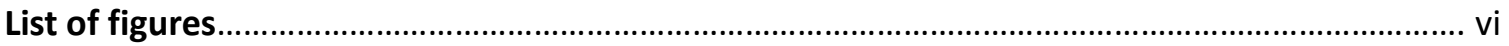

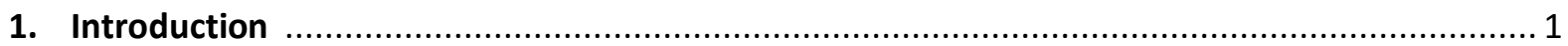

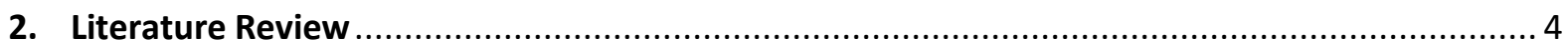

3. Cold Chain Model

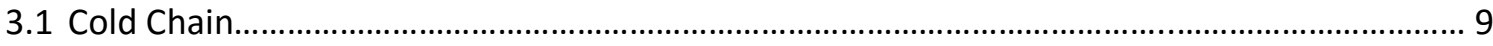

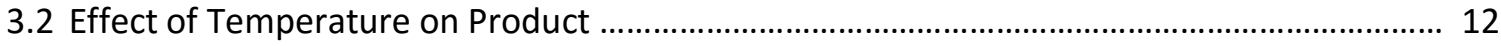

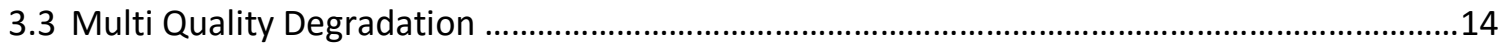

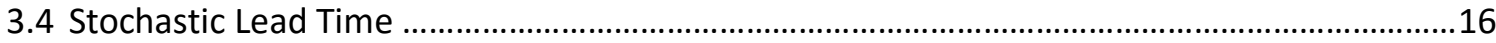

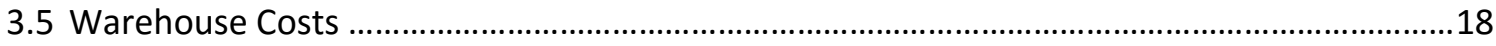

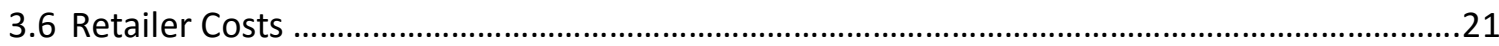

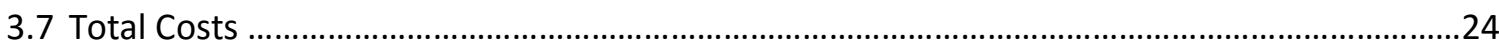

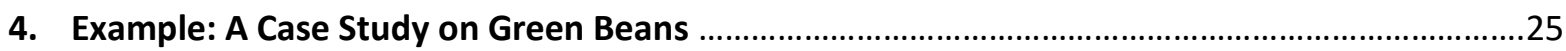

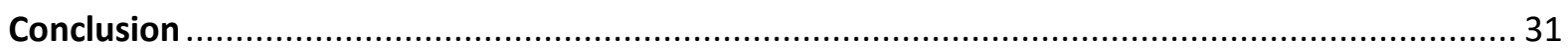

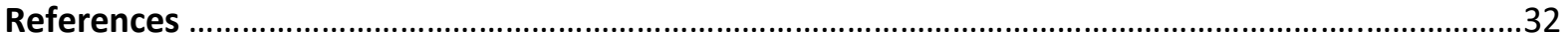

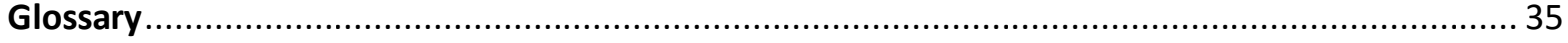




\section{List of Figures}

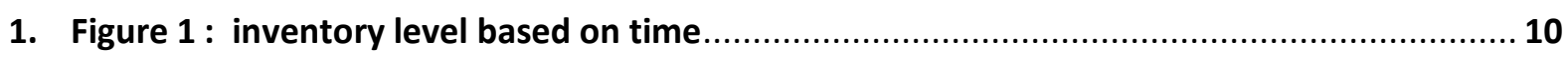

2. Figure $\mathbf{2}$ : effect of weighting factors on GSI ......................................................... 16

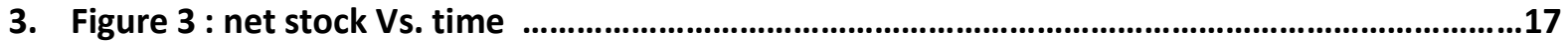

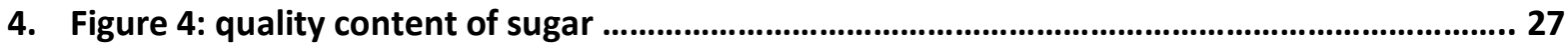

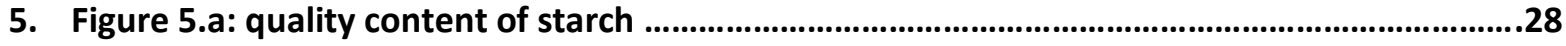

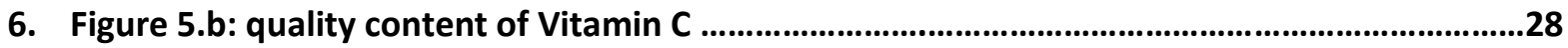

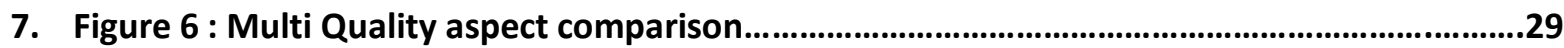

8. Figure 7 : Total cost Vs. Re-order point and number of shipments ...........................................30 


\section{Introduction}

Supply chain consists of a sequence of events and processes that are involved in the production or creation of a product or service, starting from the raw materials which undergo a series of processes until they are transformed to the final product and reach the end customer (Chopra and Meindi 2001). For example take in to account green beans. First they are picked from the fields and transported to a warehouse. From there the green beans are stored at predefined temperatures until they are ready to be transported to their final destination. After that, the green beans are loaded onto trucks, in which they are then transported to the distribution centers which there they are distributed to different retailers until they finally reach the end customer. Managers have to look into this supply chain and analyze the costs that are incurred throughout the entire process and try to reduce the costs as much as possible until it reaches its optimal level. The way each supply chain is analyzed is completely dependent on the service or product the company is selling and also the attributes that the company defines to be more important.

One type of supply chain that would be taken into account in this report is called "cold chain" which is defined by the following: products that are distributed at low temperatures in order to preserve their quality. Basically, Cold Chain has the same principles as Supply Chain except for the fact that in this chain temperature plays a very big role in the costs that are incurred for the product to reach its end consumer. In order to maintain the temperature, energy is vital to 
preserve the quality of the product, but this energy comes with a price (Zavoni and Zavanella 2011). This report will look into the quality degradation of perishable products such as fresh produce (in particular green beans). The problem with fresh produce is that their quality deterioration is highly dependent on temperature. With this deterioration of quality, the initial value of the products decrease. For retailers this has become a major issue, for example green beans are highly sensitive to temperature and cannot be stored for long periods of time. Even if the product is undergoing the best conditions, it will still degrade after time. So the main challenge for retailers is to be able to estimate the costs due to quality degradation and decide on what temperature they should store their products so it can last the most amount of time before it reaches critical quality levels.

There have been a couple methods used in order to measure quality. Peleg et al. (2002) proposed a method using Weibull Power law in order to describe the isothermal degradation of quality in foods. But one of the more commonly used methods is the first order reaction kinetics and the fractional conversions kinetics which all follow the Arrhenius behaviour (Arrhenius 1889). Most of the studies that have been conducted so far in regards to quality degradation is in respect with the Arrhenius behaviour, for this reason the author has chosen this method in order to calculate the quality levels of the product. In addition, this report has chosen to study the quality degradation of green beans as well. There have been quite some studies that have been conducted in respect to quality degradation of green beans. Martins and Silva have worked on different quality aspects of green beans such as colour and chlorophyll's, texture, Vitamin C, Sugars and starch degradation. 
To the best of the author's knowledge there has been no study in cold supply chain with regards to stochastic lead times, which give a much more realistic scenario to the real world application of cold chains. Further on, all the studies that have taken place in cold supply chain so far have defined the quality of a product by only considering one aspect of the quality of that product, for example, Blackburn and scudder (2009) and Zanoni and Zavanella (2011), but in reality the truth is that there are multiple aspects in which a product can be measured based on quality such as colour, texture, vitamins and minerals and etc. and each products quality level should be defined in respect to all relative aspects.

This report will be considering a lot-sizing problem for green beans in order to find the most efficient order quantity. This study is not just looking into only one aspect of quality for the product, but it will be looking into multiple aspects of quality by using the Global Stability Index and combining them together in order to find the overall quality of the products. Aspects such as vitamin C, colour, texture and starch. Also added stochastic lead time was added to this model in order to give a more realistic insight of the costs incurred for the supply chain of perishable products.

The remainder of this report is as follows, section 2 will be giving a brief background of the studies that have taken place so far along with their gaps and will be discussing about what has been done in order to fill that gap. Section 3 will be proposing the model along with the notations. Section 4 will be presenting a numerical study and finally, section 5 will be giving the concluding remarks along with future work. 


\section{Literature Review}

There have been many different definitions for supply chain over the years. Two of which have been presented here. "A supply chain consists of all stages involved, directly or indirectly, in fulfilling a customer request" (Chopra and Meindi 2001). "SCM is an integrative philosophy to manage the total flow of distribution channel from the supplier to ultimate user" (Cooper and Ellram 1993).

Supply chains have always been of interest to firms but lead time has caused them to compete against each other. Lead time is the time between when a company places an order and the time it actually receives it. Before the 1980's customers did not give much attention to lead time and were patient to long lead time but later on customers became intolerant to long lead times and were demanding shorter lead times which caused firms to compete against each other (Clark and Fujimoto 1989). Normally lead times are not constant and are fuzzy or stochastic, Das (1975) and Foote (1998). One of the first papers dealing with variability in lead time is Liao and Shyu (1991), they showed that with deterministic lot sizes the totals costs can be decreased by reducing the lead time. Ouyang et al. (1996) extended the model by adding stock out costs. Sajjadieh et al. (2008) developed and integrated vendor-buyer model with deterministic demand and stochastic lead time, they also allowed shortages in their model. In this report the author has integrated 
their model into a cold supply chain also with deterministic demand and stochastic lead time and shortages.

Many papers have been written in the field of managing perishable products inventory. One of the earliest papers in this area is Nahmias (1982). The models that were given attention to this field of study had a different definition of decay and degradation in products than people do today. Before the decay and degradation of quality was based upon the quantity of products (units) which had decayed or degraded. But in today's definition the degradation of quality is calculated by the level of certain aspects that the product has loss such as sugar levels, color, vitamins and bacteria levels.

For the first definition of perishable products (in terms of quantity), Ghare and Schrader (1963) developed an EOQ model for which the inventory had an exponentially distributed deterioration. Covert and Philip (1973) used an EOQ model but with an inventory deterioration following a Weibull distribution. Further on, Shah (1977) improved this model by allowing backlogs and shortages. Tadikamalla (1978) uses the EOQ model but with an inventory degradation that follows the Gamma distribution.

For the second and most recent definition of deterioration in which the product decays over time and loses value, Weiss (1982) developed a model where products have a non-linear decrease in their quality levels based on the amount of time they spend in stock or inventory. Fujiwara and Perera (1993) extend this model where inventory is managed through an EOQ model and the rate of degradation of the products (through time) follows an exponential 
distribution, however this degradation rate increases as time goes by in the inventory. Pinela et al. (2016) investigated the quality degradation and changes of post harvesting with modified atmosphere packaging (MAP) and found that with an AR-enriched atmosphere packaging, the quality of the products were much better preserved.

There have been a couple methods used in order to measure quality. Peleg et al. (2002) proposed a method using Weibull Power law in order to describe the isothermal degradation of quality in foods. The equation is shown below:

$$
\frac{q(T, t)}{q_{0}}=e^{b(T) t^{n(T)}}
$$

In which $b(T)$ and $n(T)$ are temperature dependent constants. $q_{0}$ is the initial quality and $t$ represents time. But the more widely used method for measuring quality is the first order reaction kinetics which is given below:

$$
\frac{q(T, t)}{q_{0}}=e^{k t}
$$

And the fractional conversion kinetics is shown below:

$$
\frac{q(T, t)-q_{e q}}{q_{0}-q_{e q}}=e^{k t}
$$

Following the Arrhenius behaviour for k shown below:

$$
K=k_{\text {ref }} \exp \left[-\frac{E_{a}}{R}\left(\frac{1}{T}-\frac{1}{T_{r e f}}\right)\right]
$$

In which for the mentioned notations, $q_{0}$ is the initial value of the product, $q(T, t)$ is the momentary value, $q_{e q}$ is the equilibrium value of the product, $K$ is the rate of degradation or 
kinetic rate at temperature $T$ with a storage duration of $t, k_{r e f}$ is the reference rate of degradation at reference temperature $T_{r e f}, E_{a}$ is the activation energy and finally $R$ is the universal gas constant which is approximately 8.314. This method has been used in this report in order to evaluate the quality degradation of green beans.

Later on a broader view was given to perishable products and in addition to the inventory management point of view, attention was given to more of the supply chain (Zhang et al. 2003), which developed an algorithm to optimize the costs of inventory and transportation of perishable products. Bogataj et al (2005) considers the logistics of the cold supply chain in which time and distance play an important role in the overall quality of the perishable products. Zanoni and Zavanella (2007) consider shipping multiple perishable goods from a vendor to buyer with the goal of minimizing the costs incurred due to transportation and inventory. Kuo and Chen (2010) consider a multi-temperature joint distribution center to the supply chain. Cai et al. (2010) consider the optimization and coordination of fresh product supply chains.

Despite most papers which mostly consider quality as one single aspect and measure that one aspect, Achour (2005) considers looking into multiple quality aspects and weighting each aspect based on its importance to that company or particular product. For products that degrade rapidly over time, Blackburn et al. (2004) found that their supply chain should be responsive in the early stages of the supply chain and efficient in the later stages. Blackburn and Scudder (2009) extended this model to the case of perishable produce (melons and sweet corn). Zanoni and Zavabella (2011) consider the case in which in addition to cost of quality degradation of the products, they consider the case where energy plays a big role to reduce the degradation of the products by reducing the temperatures and refrigerating the products on the producer side. This 
report has extended these models described by firstly considering multiple aspects of quality degradation and defining the critical value threshold of the products in which it should not exceed. Further on it considers the energy required to cool the products with refrigeration not only at the warehouse, but throughout the transportation from the warehouse on to the shelves of the retailer. Also the possibility of backlogs and shortages within the retailer was added and a scenario in which the transportation of products from the warehouse to the retailer has a stochastic lead time with an exponential distribution was considered. In addition to all this the average amount of time each product spends at the warehouse and on the retailer's shelf has been put into consideration. 


\section{Cold Chain Model}

\subsection{Cold Chain}

It is assumed there is a two- echelon chain of a warehouse at the upper echelon and a retailer in the lower echelon. This report is considering a perishable product such as fresh produce (green beans) and trying to capture the associated costs incurred throughout the chain from elements such as quality degradation, shortages, cooling costs, inventory costs and setup costs. It should be noted that in a two-echelon supply chain the optimal amount for $Q_{W}$ should be an integer multiple of $Q_{R}$, for this reason, $Q_{w}=n Q_{r}$ ( Silver et al. 1998). The product is first harvested from the field and later transported to the warehouse. It is assumed, as long as the produce is in the field and attached to the plant, there is no degradation of quality. But as soon as it is detached from the plant is when the quality degradation begins. This period of harvesting is in the first period in which it spends a time of $t_{1}$ with temperature $T_{1}$. Moreover in period 2 the produce spends a constant time of $t_{2}$ with temperature $T_{1}$ to get to the warehouse. There the produce spends an average time of $t_{3}$ in the warehouse with temperature $T_{3}$. In order to calculate the average time spent in the warehouse first the total inventory is calculated, which is shown below: 


\section{Inventory Level}

Qw

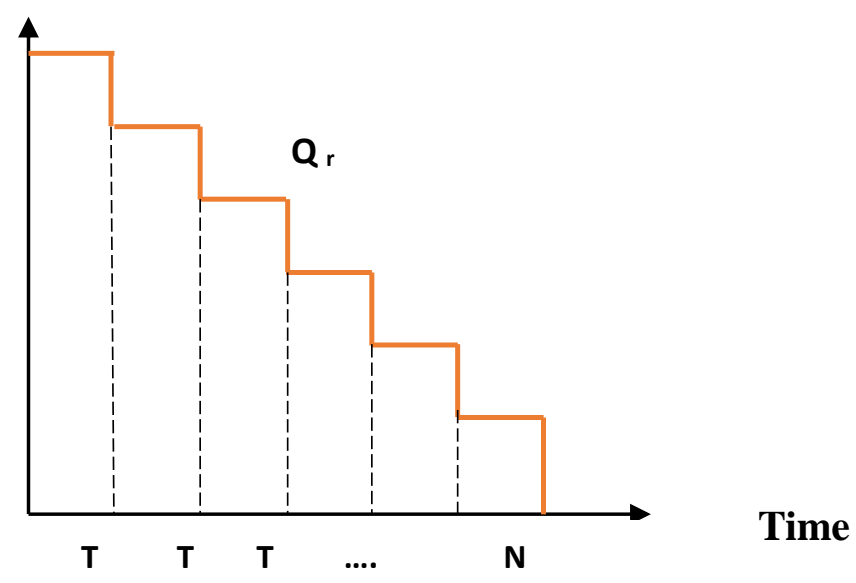

Figure 1-inventory level shown based on time

The following equation is known:

$$
\frac{Q_{w}}{D}=n T \rightarrow T=\frac{Q_{r}}{D}
$$

From the total inventory can be calculated, which is shown in the equation below:

Total inventory $=T\left(Q_{w}-Q_{r}\right)+T\left(Q_{w}-2 Q_{r}\right)+T\left(Q_{w}-3 Q_{r}\right)+\cdots+T\left(Q_{w}-(n) Q_{r}\right)$

$=\mathrm{T}\left[n Q_{w}-Q_{r}-2 Q_{r}-3 Q_{r}-\cdots-(n) Q_{r}\right]=T\left[n Q_{w}-\frac{n Q_{r}}{2}(n+1)\right]=\frac{Q_{r}}{D}\left[n Q_{w}-\frac{n Q_{r}}{2}(n+1)\right]$

(6)

The average inventory can be calculated by dividing the total inventory by the total time spent in the warehouse which is shown below: 
average inventory at warehouse: $\frac{Q_{r}}{D}\left[n Q_{w}-\frac{n Q_{r}}{2}(n+1)\right]=n \frac{Q_{r}}{D} \times h e i g h t \rightarrow$

height $=Q_{w}-\frac{Q_{r}}{2}(n+1)=n Q_{r}-\frac{Q_{r}}{2}(n+1)=Q_{r}\left[n-\frac{(n+1)}{2}\right]=Q_{r} \frac{(n-1)}{2}$

$\rightarrow$ Average inventory at warehouse: $Q_{r} \frac{(n-1)}{2}$

In order to calculate the average time spent in the warehouse, $t_{3}$, for each product, the average inventory obtained from Equation ( 7 ) is divided by the constant demand $D$, shown below:

$$
t_{3}=\frac{Q_{r}}{2 D}(n-1)
$$

Moreover after spending time in the warehouse, the fresh produce (green beans) is transported to the retailer but the time it takes for the product to get to the retailer is assumed to have a stochastic lead time with an exponential distribution. This time is known as $t_{4}$ and the temperature throughout this time in the transporting vehicle is $T_{4}$. Stochastic lead time has been used in many papers, for example, Kaplan (1970) constructed a dynamic inventory model with a stochastic lead time, Tang and Grubbstrom (2005) had put in place stochastic lead time in a manufacturing and remanufacturing system with deterministic demand. After the product reached the retailer it undergoes a certain amount of time, $t_{5}$, on the shelves with a retailer temperature of $T_{5}$ throughout the entire store. In order to calculate this time the average amount of time each product spends on the shelves with respect to the constant demand of $D$ shall be considered. Much like the previous method, the average inventory of the retailer is divided by demand in order to calculate the average time each product spends on the shelves, as shown in the equations below: 
average inventory at retailer $=\frac{Q_{r}}{2}$

$t_{5}=\frac{Q_{r}}{2 D}$

The diagram below shows the activities that each product goes through with the time and temperature label, until it reaches the hands of the end consumer.

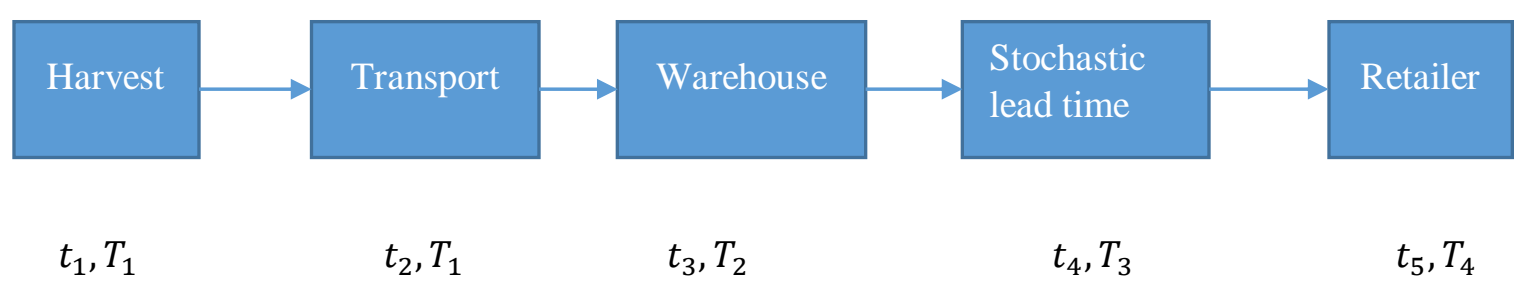

\subsection{Effects of temperature on product}

Fresh produce and foods go through undesirable changes which are highly dependent on the temperature in which they are placed. According to Peleg et al. (2002) these undesirable changes are linked directly to the temperatures in which these products are placed in. From the Arrhenius equations presented in Equation (2) and Equation (3) and according to Peleg et al. (2002) with the Weibull power law presented in Equation (1), it can be seen that the ratio of the momentary and initial quality of products have a direct relationship with the temperature in which they are placed in. Of course keeping these products at low temperatures requires a price in which accommodates them. Rong et al. (2011) proposed a coefficient of performance (COP) in which the energy consumption of each product can be compared at a specific temperature based on their reference temperature. The Coefficient of Performance is shown below:

$C O P_{\text {cooling }}=\frac{Q_{\text {cold }}}{Q_{\text {hot }}-Q_{\text {cold }}}=\frac{T_{\text {cold }}}{T_{\text {hot }}-T_{\text {cold }}}=\rho$ 
$\mathbf{Q}_{\text {cold }}=$ heat taken in by cold heat reservoir (joule)

$\mathbf{Q}_{\text {hot }}=$ heat taken in by hot heat reservoir (joule)

$\mathbf{T}_{\text {cold }}=$ Absolute temperature of cold reservoir $\left({ }^{\circ} \mathrm{K}\right)$

$\mathbf{T}_{\text {hot }}=$ Absolute temperature of hot reservoir $\left({ }^{\circ} \mathrm{K}\right)$

An example of this has been shown in Zanoni and Zavanella (2011) in which they compared the energy consumed to freeze a product at a temperature of $-20^{\circ} \mathrm{C}$ compared to its planned temperature of $-30^{\circ} \mathrm{C}$. It should be noted that the reference temperature is assumed to be the average outside temperature as $20^{\circ} \mathrm{C}$. In this example we are comparing the temperatures of $-5^{\circ} \mathrm{C}$ and $-10^{\circ} \mathrm{C}$ which is shown below:

It's known that ${ }^{\circ} \mathrm{K}=273.15+{ }^{\circ} \mathrm{C}$ so,

$\operatorname{COP}_{-10^{\circ} \mathrm{C}}=\frac{273.15-10}{(273.15+20)-(273.15-10)}=8.77$

$\mathrm{COP}_{-5^{\circ} \mathrm{C}}=\frac{273.15-5}{(273.15+20)-(273.15-5)}=10.72$

$\rho=\frac{C O P_{-10^{\circ} C}}{C O P_{-5^{\circ} C}}=\frac{8.77}{10.72}=0.818$

This ratio $(\rho)$ indicates that the energy required to cool the products at $-5^{\circ} \mathrm{C}$ requires $81.8 \%$ of that required to cool them at $-10^{\circ} \mathrm{C}$. Of course the lower the temperature in which the products are stored in, the less degradation the products go through, but this also incurs more costs and this is why it is very vital to find the most optimal temperature in order to keep the product at an efficient quality level and also keep costs to a minimum. 


\subsection{Multi-Quality Degradation}

As already discussed, the products degrade in terms of quality throughout time in a rate which is based on the temperature in which they are stored in. The most common model used in order to describe the relationship between the degradation of products and the temperature they are stored in is the Arrhenius equation (Rao and Rizvi 1986) shown in Equation (2) and Equation (3) along with the method for calculating the value of " $k$ " shown in Equation (4).

Although Equation (2) and Equation (3) both represent degradation in food but it has been found that some quality aspects of products follow the first order kinetic reaction, Equation (2) and other aspects follow the fractional conversion kinetics, Equation (3).

$$
\begin{gathered}
\frac{q_{i}}{q_{i 0}}=e^{k t} \\
\frac{q_{i}-q_{i e q}}{q_{i 0}-q_{i e q}}=e^{k t}
\end{gathered}
$$

For example, according to Giannakourou and taoukis (2003) for green beans they show that vitamin C loss follows Equation (2) and according to Martins and Silva (2003) they show that quality changes such as Texture, Vitamin C, Sugars and Starch also follow Equation (2) but according to Martins and Silva (2000), it's shown that Chlorophyll's change (which contributes to colour change) follow the fractional conversion kinetics, Equation (3).

In this report multi-quality aspects are being used in order to estimate the total quality loss. It's known that fresh produce products are not rated only based on one particular aspect of quality. 
For example green beans are in interest of customers not only because of their aesthetic appearance (such as colour) but also because of their nutritional values such as Vitamin C levels or their taste which corresponds to the level of sugar it holds and other aspects such as texture and starch. For this reason in this research the Global Stability Index (Achour 2005) is being used in order to estimate the overall quality levels of the product. GSI (Global Stability Index) is shown in Equation (12).

$$
\mathrm{GSI}=1-\sum_{i=1}^{z} \gamma_{i} e^{k t}
$$

Where $\gamma_{i}$ is the weight factor or the level of importance given to each quality aspect of a specific product and $\sum_{i=1}^{z} \gamma_{i}=1$. Also it should be noted that " $\mathrm{z}$ " is the total number of quality aspects that are being considered for the product. Moreover by recalling Equation (2) and Equation (3), $e^{k t}$ indicates the ratio of the momentary quality level of the product compared to its original state. In order to estimate the total loss of quality with respect to all aspects and their weights it is subtracted from 1, Equation (12). An example of the GSI has been shown in figure 2. 


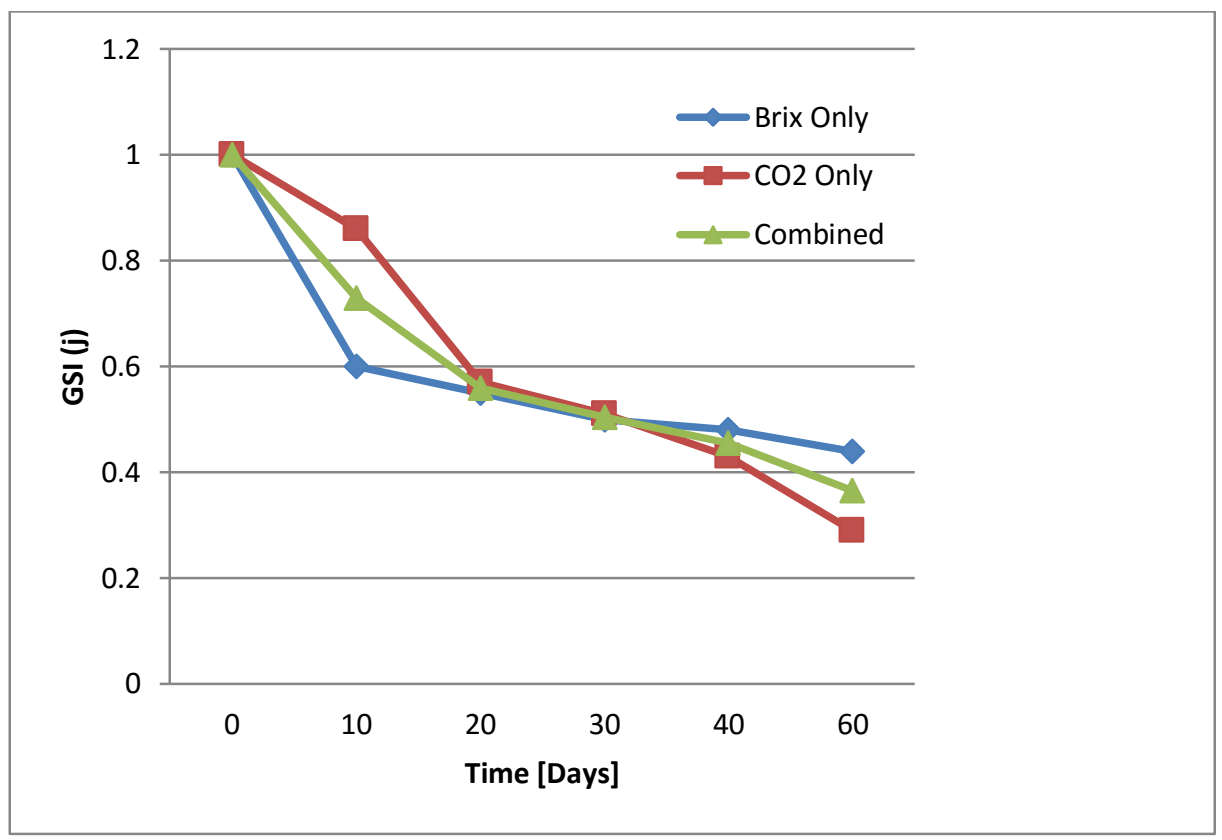

Figure 2- effect of weighting factors on GSI from Achour (2005)

Figure 2 shows the degradation level of an orange-based carbonated beverage. Two aspects of quality have been evaluated such as, Brix $(\mathrm{g} / \mathrm{g})$ and $\mathrm{CO}_{2}$ (lit/lit). These two aspects have been considered under three scenarios. Scenario 1 , which is labeled brix only has a weight of 0.9 for Brix and a weight of 0.1 for $\mathrm{CO}_{2}$. Scenario 2, labeled as $\mathrm{CO}_{2}$ only has given a weight of 0.9 for $\mathrm{CO}_{2}$ and a weight of 0.1 for Brix. The third scenario labeled as combined, has contributed both aspects with equal quality, meaning a weight of 0.5 has been given to both $\mathrm{CO}_{2}$ and Brix. Figure 2 , clearly illustrates a decrease in quality levels of the beverage with different variations with respect to the importance of each aspect for quality.

\subsection{Stochastic Lead Time}

According to Sajadie et al.(2008), most firms undergo a stochastic lead time which is not constant. They combined stochastic lead time along with shortages in a two stage supply chain. 
They assumed an exponential distribution for lead time. The probability density function is shown in Equation (13).

$$
f(l)=\lambda e^{-\lambda l}
$$

Sajadie et al.(2008) presented the following equation in order to calculate the buyer expected cost during an order cycle shown below, in this equation the author looks in to three cases. Case 1 is for when the lead time is less then $\frac{r}{D^{\prime}}$ in other words before there is a shortage. Case 2 looks into when the lead time is long enough to cause a shortage but not that much to cause negativity in the net stock. Case 3 is for when the lead time is so long that even after replenishment out net stock is negative.

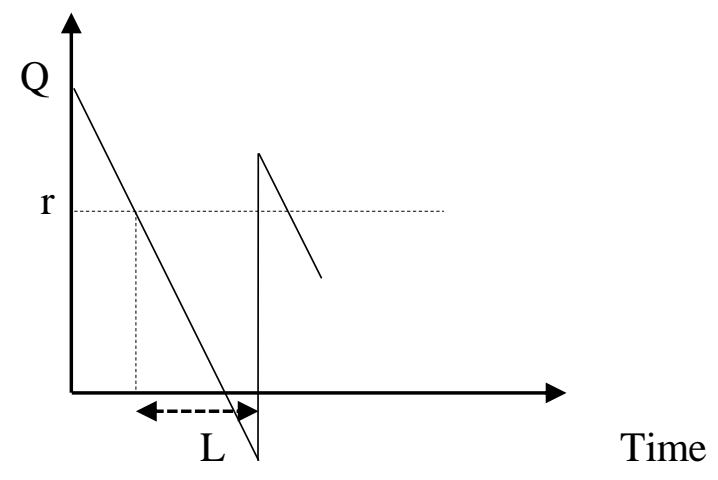

Figure 3- Net stock vs. Time

expected holding cost: $\boldsymbol{h}_{\boldsymbol{b}} \int_{\mathbf{0}}^{\frac{r}{D}}\left(\frac{Q_{r}}{2}+\boldsymbol{r}-\boldsymbol{D} \boldsymbol{l}\right) \boldsymbol{f}(\boldsymbol{l}) \boldsymbol{d l}+\int_{\frac{r}{D}}^{\frac{r+Q_{r}}{D}}\left[\frac{\pi(D l-r)^{2}}{2 Q_{r}}+\frac{\boldsymbol{h}_{b}\left(\boldsymbol{Q}_{r}+r-D l\right)^{2}}{2 Q_{r}}\right] \boldsymbol{f}(\boldsymbol{l}) \boldsymbol{d l}+$ $\int_{\frac{r+Q_{r}}{D}}^{\infty} \pi\left(D l-r-\frac{Q_{r}}{2}\right) f(l) d l$ 
By substituting Equations (13) to (14) we have:

expected holding cost: $\boldsymbol{h}_{r}\left(\boldsymbol{r}+\frac{\boldsymbol{Q}_{\boldsymbol{r}}}{2}-\frac{\boldsymbol{D}}{\lambda}\right)+\frac{D^{2}\left(\boldsymbol{\pi}+\boldsymbol{h}_{\boldsymbol{r}}\right)}{\lambda^{2} \boldsymbol{Q}_{r}}\left(e^{-\frac{\boldsymbol{r} \lambda}{D}}-e^{-\frac{\left(\boldsymbol{r}+\boldsymbol{Q}_{r}\right) \lambda}{D}}\right)$

The expected quality level reached for each aspect can be shown in Equation (16). (Take in to note that the stochastic lead time occurs in period $t_{4}$ with transportation temperature of $T_{3}$.) expeced quality level: $\boldsymbol{q}_{i 0} \int_{0}^{\infty}\left(e^{-\alpha_{i}\left(T_{3}\right) l}\right) f(l) d \boldsymbol{l}=\lambda \boldsymbol{q}_{i 0} \int_{0}^{\infty}\left(e^{-\alpha_{i}\left(T_{3}\right) l}\right)\left(e^{-\lambda l}\right) d \boldsymbol{l}=$

$q_{i 0} \frac{\lambda}{\lambda+\alpha_{i}\left(T_{3}\right)}$

In order to estimate the GSI of all aspects through this period with respect to Equation (12) the weight of each quality aspect is multiplied to the expected quality level for each aspect which is shown in Equation (17).

Quality level of all aspects combined: $\sum_{1}^{z} q_{i 0} \gamma_{i} \frac{\lambda}{\lambda+\alpha_{i}\left(T_{3}\right)}$

loss of quality of all aspects combined: $1-\sum_{1}^{z} q_{i 0} \gamma_{i} \frac{\lambda}{\lambda+\alpha_{i}\left(T_{3}\right)}$

\subsection{Warehouse Costs}

This section of the report shall be based upon modelling the equations necessary to determine the costs of the chain from when the product is harvested from the fields and is transported to the warehouse. Factors such as inventory costs, quality degradation and setup costs will be evaluated. 
Setup Costs: This cost consists of two components, one in which is the fixed annual costs of the warehouse and the second part is the variable annual costs of the warehouse for cooling the products which are dependent on the equipment needed in order to store them at a specific temperature.

$$
\frac{A_{w} D}{Q_{w}}+\rho_{w} \cdot \beta_{w} \cdot D
$$

The second component consists of many aspects such as the equipment necessary to cool the products to a specific temperature, the capacity required by the equipment, maintenance costs of the equipment, etc. Moreover it is calculated by multiplying the average setup cost per kg of products, $\beta_{w}$, the average annual demand, D and the coefficient of performance of the warehouse with temperature $\mathrm{T}_{2}, \rho_{w}$.

Holding Cost: This cost also consists of two components, the first is the average fixed cost of maintaining the products without considering the cooling costs associated with it and the second component takes into account the energy consumption required to cool the products which depends on the amount of products being stored in the inventory and is calculated by multiplying the average inventory level of the warehouse, the energy consumption (kWh) required in order to cool one $\mathrm{kg}$ of each product in the warehouse, $E_{w}$, the cost of cooling for each $\mathrm{kWh}$ in the warehouse, $C_{w}$ and coefficient of performance (COP) at different temperature levels compared to the reference temperature, $\rho_{w}$. With respect to Equation (7) for the average inventory level at the warehouse the holding costs of the warehouse can be shown in Equation (20).

Holding cost of warehouse: $\boldsymbol{h}_{w} \boldsymbol{Q}_{r} \frac{(\boldsymbol{n}-\mathbf{1})}{2}+\boldsymbol{E}_{w} \boldsymbol{C}_{w} \boldsymbol{\rho}_{w}$ 
Quality Loss and Degradation: Throughout the chain from when the very moment the products are being detached from the plant and when it is being transported to the warehouse and the time in which it spends at the warehouse until it is shipped to the retailer it degrades and this degradation comes with a price.

First, let's consider the first two stages in which the product is being harvested and later transported to the warehouse. Assume the $x^{\text {th }}$ unit is picked from a batch of size $Q_{w}$. This $x^{\text {th }}$ unit is held for a time of $t_{1}=\frac{Q_{w}-x}{p}$ (Notice $\mathrm{p}$ is the picking rate). Later when the batch is full it is transported with a fixed time of $t_{2}$. In addition to this it should be noted that the temperature of the products throughout this time period is $T_{1}$. The quality degradation of each aspect with respect to GSI is shown in Equation (21) throughout this time until the end of period $t_{2}$.

$\left(\mathrm{Q}_{\mathrm{w}}=\mathrm{nQ} \mathrm{Q}_{\mathrm{r}}\right.$

$V . G S I\left(t_{2}\right)=V \sum_{i=1}^{z} \gamma_{i}\left[\int_{0}^{n Q_{r}} 1-e^{-\alpha_{i}\left(T_{1}\right)\left(\frac{n Q_{r}-x}{p}\right)} e^{-\alpha_{i}\left(T_{1}\right) t_{2}}\right]=V \sum_{i=1}^{z} \gamma_{i}\left[\int_{0}^{n Q_{r}} d x-\right.$ $\left.\int_{0}^{n Q_{r}} e^{-\alpha_{i}\left(T_{1}\right)\left(\frac{n Q_{r}-x}{p}\right)} e^{-\alpha_{i}\left(T_{1}\right) t_{2}} d x\right]=V \gamma_{i}\left[n Q_{r}-\sum_{i=1}^{Z} \frac{p}{\alpha_{i}\left(T_{1}\right)} e^{-\alpha_{i}\left(T_{1}\right) t_{2}}(1-\right.$ $\left.\left.e^{\frac{\alpha_{i}\left(T_{1}\right) n Q_{r}}{p}}\right)\right]$

From here the products spend an average time period of $t_{3}$ which was calculated in Equation (8) with a warehouse temperature of $T_{2}$. The quality degradation of the products in the warehouse until the end of period $t_{3}$ is shown in Equation (22).

$V . G S I\left(t_{3}\right)=\sum_{i=1}^{Z} V \gamma_{i}\left[n Q_{r}-\frac{p}{\alpha_{i}\left(T_{1}\right)} e^{-\alpha_{i}\left(T_{1}\right) t_{2}} \cdot e^{-\alpha_{i}\left(T_{2}\right) t_{3}}\left(1-e^{-\frac{\alpha_{i}\left(T_{1}\right) n Q_{r}}{p}}\right)\right]$ 
The total costs for the warehouse until the end of period $t_{3}$ is calculated by adding Equations (19), (20) and (22). (Equation 22 is multiplied by $D / \mathrm{nQ}_{r}$ because this degradation happens for each order cycle).

$T C_{w}\left(Q_{r}, T_{1}, T_{2}, n\right)=\frac{A_{w} D}{Q_{w}}+\rho_{w} \cdot \beta_{w} . D+h_{w} Q_{r} \frac{(n-1)}{2}+E_{w} \cdot C_{w} \cdot \rho_{w}+\frac{D}{n Q_{r}} \sum_{i=1}^{z} V \gamma_{i}\left[n Q_{r}-\right.$

$\left.\frac{p}{\alpha_{i}\left(T_{1}\right)} e^{-\alpha_{i}\left(T_{1}\right) t_{2}} \cdot e^{-\alpha_{i}\left(T_{2}\right) t_{3}}\left(1-e^{-\frac{\alpha_{i}\left(T_{1}\right) n Q_{r}}{p}}\right)\right]$

\subsection{Retailer Costs}

Much like the Costs associated with the warehouse, the retailer costs consist of much of the same theory. Similar to the previous section, here the setup costs will be discussed once again, the holding and ordering costs, the costs associated with the degradation of quality both throughout its lead time and in the retailer.

Setup Costs: This cost consists of two components, one in which is the fixed annual costs of the retailer and the second part is the variable annual costs of the retailer for cooling the products which is dependent on the equipment needed in order to store them at a specific temperature. The second component consists of aspects such as the equipment necessary to cool the products to a specific temperature, the capacity required by the equipment, maintenance costs of the equipment, etc. Moreover it is calculated by multiplying the average setup costs of the equipment, $A_{r}$, the average setup cost per kg of products, $\beta_{r}$, the average annual demand, $\mathrm{D}$ and the coefficient of performance of the retailer with temperature $T_{5}, \rho_{r}$ This is shown in Equation (24). 


$$
\frac{A_{r} D}{Q_{r}}+\rho_{r} \cdot \beta_{r} \cdot D
$$

Holding Costs and Ordering Costs: According to what has been said in section 3.5 of this report and based on Equation (15) the expected cost of holding and ordering the products for the retailer based on an exponential distribution for the lead time is shown below:

expected ordering and holding costs: $\boldsymbol{h}_{\boldsymbol{r}}\left(\boldsymbol{r}+\frac{\boldsymbol{Q}_{r}}{2}-\frac{\boldsymbol{D}}{\lambda}\right)+\frac{\boldsymbol{D}^{2}\left(\pi+\boldsymbol{h}_{r}\right)}{\lambda^{2} \boldsymbol{Q}_{r}}\left(\boldsymbol{e}^{-\frac{\boldsymbol{r} \lambda}{D}}-e^{-\frac{\left(\boldsymbol{r}+\boldsymbol{Q}_{r}\right) \lambda}{D}}\right)$

Quality Loss and Degradation: In this part of the chain the products go through degradation from when they are being transported from the warehouse to the retailer with stochastic lead time of $t_{4}$ and when they arrive at the retailer they spend an average of $t_{5}$ each. For the first part of the degradation which occurs in period $t_{4}$ the product degrades. Because this period is stochastic and not constant the expected degradation of the product will be considered. As shown in Equation (18) the quality value for all aspects with temperature level $\mathrm{T}_{3}$ is shown below:

$$
\operatorname{V.GSI}\left(t_{4}\right): \sum_{1}^{Z} V \gamma_{i} \frac{\lambda}{\lambda+\alpha_{i}\left(T_{3}\right)}
$$

Further on when the products reach the retailer they spend an average time of $t_{5}$. As discussed before this average amount of time in which the products are on the shelves is shown in Equation (10) $\left(t_{5}=\frac{Q_{r}}{2 D}\right)$. The quality loss of all aspects only in period $t_{5}$ is shown below:

$$
\text { quality value for period } t_{5}: V \sum_{1}^{z} e^{-\alpha_{i}\left(T_{4}\right) t_{5}}
$$

In order for us to determine the total loss of quality between periods $t_{4}$ and $t_{5}$ the total loss of quality until the end of period $t_{5}$ will be subtracted from the total loss of quality until the end of 
period $t_{3}$,Equation (22), with respect to all aspects. The quality loss at the end of period $t_{5}$ is calculated by multiplying Equations (18) and (25) and placing in Equation (22) as shown below:

$$
\begin{aligned}
\operatorname{V.GSI}\left(t_{5}\right)= & \sum_{i=1}^{z} V \gamma_{i}\left[n Q_{r}\right. \\
& \left.-\frac{p}{\alpha_{i}\left(T_{1}\right)} e^{-\alpha_{i}\left(T_{1}\right) t_{2}} \cdot e^{-\alpha_{i}\left(T_{2}\right) t_{3}} \cdot \gamma_{i} \frac{\lambda}{\lambda+\alpha_{i}\left(T_{3}\right)} e^{-\alpha_{i}\left(T_{4}\right) t_{5}}\left(1-e^{-\frac{\alpha_{i}\left(T_{1}\right) n Q_{r}}{p}}\right)\right]
\end{aligned}
$$

By subtracting Equation (26) from Equation (22), the total quality loss between periods $t_{4}$ and $t_{5}$ will be obtained. This is shown in Equation (27).

$$
\begin{aligned}
& V .\left[G S I\left(t_{5}\right)-G S I\left(t_{3}\right)\right]=\frac{D}{n Q_{r}} \sum_{i=1}^{Z} V \gamma_{i}\left[n Q_{r}-\right. \\
& \sum_{i=1}^{Z} \gamma_{i} \frac{p}{\alpha_{i}\left(T_{1}\right)} e^{-\alpha_{i}\left(T_{1}\right) t_{2}} \cdot e^{-\alpha_{i}\left(T_{2}\right) t_{3}} \cdot \gamma_{i} \frac{\lambda}{\lambda+\alpha_{i}\left(T_{3}\right)} e^{-\alpha_{i}\left(T_{4}\right) t_{5}}\left(1-e^{-\frac{\alpha_{i}\left(T_{1}\right) n Q_{r}}{p}}\right)-\sum_{i=1}^{Z} V \gamma_{i}\left[n Q_{r}-\right. \\
& \left.\left.\sum_{i=1}^{Z} \gamma_{i} \frac{p}{\alpha_{i}\left(T_{1}\right)} e^{-\alpha_{i}\left(T_{1}\right) t_{2}} \cdot e^{-\alpha_{i}\left(T_{2}\right) t_{3}}\left(1-e^{-\frac{\alpha_{i}\left(T_{1}\right) n Q_{r}}{p}}\right)\right]\right] \\
& =\frac{D}{Q_{r}} \sum_{1}^{Z} V \gamma_{i}\left[\frac{p}{\alpha_{i}\left(T_{1}\right)} e^{-\alpha_{i}\left(T_{1}\right) t_{2}} . e^{-\alpha_{i}\left(T_{2}\right) t_{3}}\left(1-e^{-\frac{\alpha_{i}\left(T_{1}\right) n Q_{r}}{p}}\right)\right. \\
& -\frac{p}{\alpha_{i}\left(T_{1}\right)} e^{-\alpha_{i}\left(T_{1}\right) t_{2}} \cdot e^{-\alpha_{i}\left(T_{2}\right) t_{3}} \cdot \gamma_{i} \frac{\lambda}{\lambda+\alpha_{i}\left(T_{3}\right)} e^{-\alpha_{i}\left(T_{4}\right) t_{5}}(1 \\
& \left.\left.-e^{-\frac{\alpha_{i}\left(T_{1}\right) n Q_{r}}{p}}\right)\right]
\end{aligned}
$$


Total Costs of Retailer: The total costs for the retailer consists of the sum of Equations (27), and (24) and is shown below:

$T C_{r}\left(Q_{r}, T_{1}, T_{2}, T_{3}, T_{4}, n\right)=\frac{A_{r} D}{Q_{r}}+\rho_{r} \cdot \beta_{r} . D+h_{r}\left(r+\frac{Q_{r}}{2}-\frac{D}{\lambda}\right)+\frac{D^{2}\left(\pi+h_{r}\right)}{\lambda^{2} Q_{r}}\left(e^{-\frac{r \lambda}{D}}-e^{-\frac{\left(r+Q_{r}\right) \lambda}{D}}\right)+$ $\frac{D}{Q_{r}} \sum_{1}^{Z} V \gamma_{i}\left[\frac{p}{\alpha_{i}\left(T_{1}\right)} e^{-\alpha_{i}\left(T_{1}\right) t_{2}} \cdot e^{-\alpha_{i}\left(T_{2}\right) t_{3}}\left(1-e^{-\frac{\alpha_{i}\left(T_{1}\right) n Q_{r}}{p}}\right)-\right.$

$\left.\frac{p}{\alpha_{i}\left(T_{1}\right)} e^{-\alpha_{i}\left(T_{1}\right) t_{2}} \cdot e^{-\alpha_{i}\left(T_{2}\right) t_{3}} \cdot \gamma_{i} \frac{\lambda}{\lambda+\alpha_{i}\left(T_{3}\right)} e^{-\alpha_{i}\left(T_{4}\right) t_{5}}\left(1-e^{-\frac{\alpha_{i}\left(T_{1}\right) n_{2}}{p}}\right)\right]$

\subsection{Total Costs}

The total cost of the supply chain can be calculated by adding the total costs of the warehouse ,Equation (23) with the total costs of the retailer, Equation (28).

$$
\begin{aligned}
& T C\left(Q_{r}, T_{1}, T_{2}, T_{3}, T_{4}, n\right)=\frac{A_{w} D}{Q_{w}}+\rho_{w} \cdot \beta_{w} . D+h_{w} Q_{r} \frac{(n-1)}{2}+E_{w} \cdot C_{w} \cdot \rho_{w}+ \\
& \frac{D}{n Q_{r}} \sum_{i=1}^{z} V \gamma_{i}\left[n Q_{r}-\sum_{i=1}^{z} \gamma_{i} \frac{p}{\alpha_{i}\left(T_{1}\right)} e^{-\alpha_{i}\left(T_{1}\right) t_{2}} \cdot e^{-\alpha_{i}\left(T_{2}\right) t_{3}}\left(1-e^{-\frac{\alpha_{i}\left(T_{1}\right) n Q_{r}}{p}}\right)\right]+\frac{A_{r} D}{Q_{r}}+\rho_{r} \cdot \beta_{r} \cdot D+ \\
& h_{r}\left(r+\frac{Q_{r}}{2}-\frac{D}{\lambda}\right)+\frac{D^{2}\left(\pi+h_{r}\right)}{\lambda^{2} Q_{r}}\left(e^{-\frac{r \lambda}{D}}-e^{-\frac{\left(r+Q_{r}\right) \lambda}{D}}\right)+\frac{D}{Q_{r}} \sum_{1}^{z} V \gamma_{i}\left[\frac{p}{\alpha_{i}\left(T_{1}\right)} e^{-\alpha_{i}\left(T_{1}\right) t_{2}} \cdot e^{-\alpha_{i}\left(T_{2}\right) t_{3}}(1-\right. \\
& \left.\left.e^{-\frac{\alpha_{i}\left(T_{1}\right) n Q_{r}}{p}}\right)-\frac{p}{\alpha_{i}\left(T_{1}\right)} e^{-\alpha_{i}\left(T_{1}\right) t_{2}} \cdot e^{-\alpha_{i}\left(T_{2}\right) t_{3}} \cdot \gamma_{i} \frac{\lambda}{\lambda+\alpha_{i}\left(T_{3}\right)} e^{-\alpha_{i}\left(T_{4}\right) t_{5}}\left(1-e^{-\frac{\alpha_{i}\left(T_{1}\right) n Q_{r}}{p}}\right)\right]
\end{aligned}
$$




\section{Example: A case study on green beans}

To further explore the model, a case study on green beans had been conducted. For this study three quality aspects of green beans had been chosen, Vitamin C, Starch and Sugar content. The following assumptions were made, Demand is 1000 units/year, the picking rate is 10 units, reorder point for buyer is 100 units, setup cost at warehouse is 5 , setup cost at retailer is 5 , Energy consumption is 0.2 , cost of cooling energy is 1 , inventory cooling cost at warehouse is 0.1 , inventory holding cost at retailer is 0.1 , shortage cost for retailer is 0.1 , lead time is 5 and the initial value of product is 5 .

It is assumed green beans are first harvested from the field and placed in a basket. Also it has been put into consideration that, after the green beans have been picked, is when the quality degradation begins. The temperature of the outside field is assumed to be $30^{\circ} \mathrm{C}$, after they have been picked it takes a constant amount of time $t_{2}\left(t_{2}=0.5\right)$ to transfer them to the warehouse. In there the beans are kept as inventory until they are shipped to the retailer. The temperature within the warehouse is also assumed to be $-10^{\circ} \mathrm{C}$. When the green beans are getting ready to be shipped to the retailer they are placed in a trailer, the trailer is also assumed to have an inside temperature of $-10^{\circ} \mathrm{C}$. At the final stage the green beans are placed on the shelves of the retailer in which they are kept until a customer picks them, the temperature within the retailer is assumed to be $22^{\circ} \mathrm{C}$. For simplicity we assume that the COP for the retailer and the warehouse are equal. In order to calculate the COP the following calculations have been conducted. The reference temperature is assumed to be $-20^{\circ} \mathrm{C}$. 


$$
\begin{aligned}
& \operatorname{COP}_{-30^{\circ} \mathrm{C}}=\frac{-30+273.15}{(-30+273.15)-(-20+273.15)}=-24.315 \\
& \operatorname{COP}_{-25^{\circ} \mathrm{C}}=\frac{-25+273.15}{(-25+273.15)-(-20+273.15)}=-49.63
\end{aligned}
$$

Therefore the ratio for the required energy to keep green beans at $-25^{\circ} \mathrm{C}$ compared to $-30^{\circ} \mathrm{C}$ has been calculated below:

$$
\rho=\frac{\operatorname{COP}_{-30^{\circ} \mathrm{C}}}{\operatorname{COP}_{-25^{\circ} \mathrm{C}}}=\frac{-24.315}{-49.63}=0.49
$$

In other words, the energy required to cool green beans at $-25^{\circ} \mathrm{C}$ is $49 \%$ of that required to cool them at $-30^{\circ} \mathrm{C}$.

In this research the quality levels of three aspects have been put into consideration. The graphs below illustrate the behaviour of the three quality aspects in three different temperatures, $15^{\circ} \mathrm{C},-7^{\circ} \mathrm{C}$ and $0^{\circ} \mathrm{C}$. The results of the analysis are shown below: 


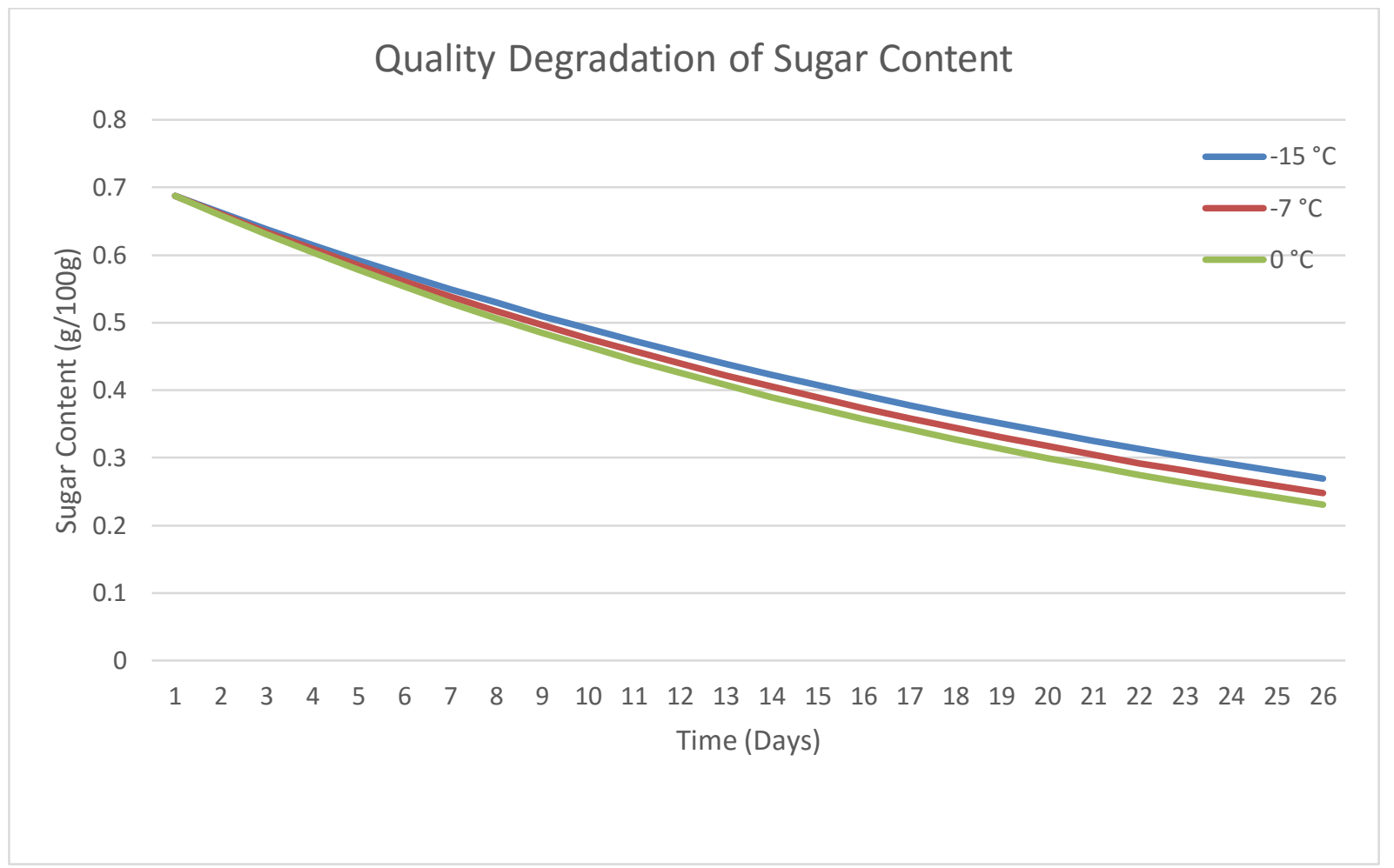

Figure 4: The quality degradation of Sugar content has been given in three temperatures of $-15^{\circ} \mathrm{C},-7^{\circ} \mathrm{C}$ and $0^{\circ} \mathrm{C}$.

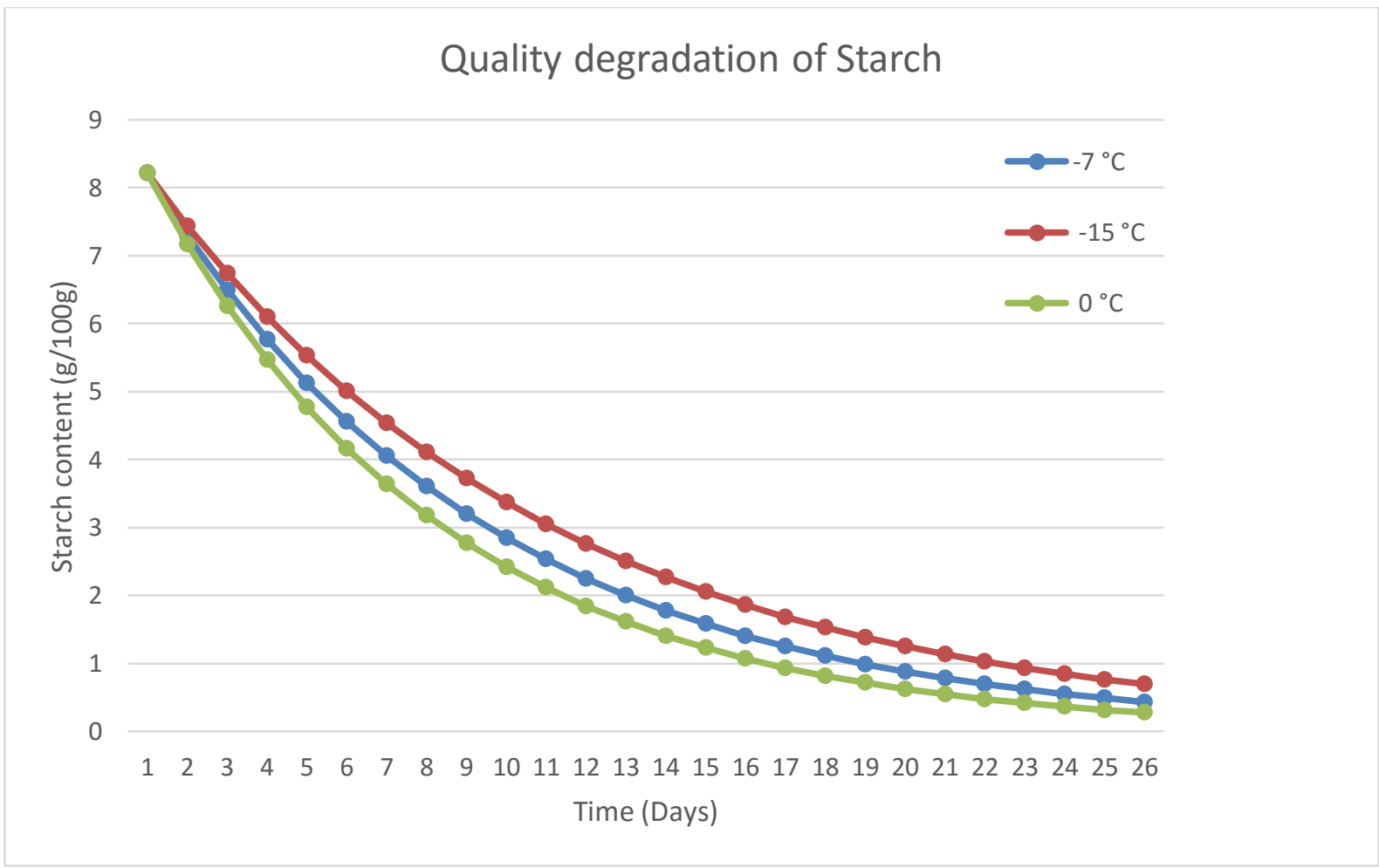




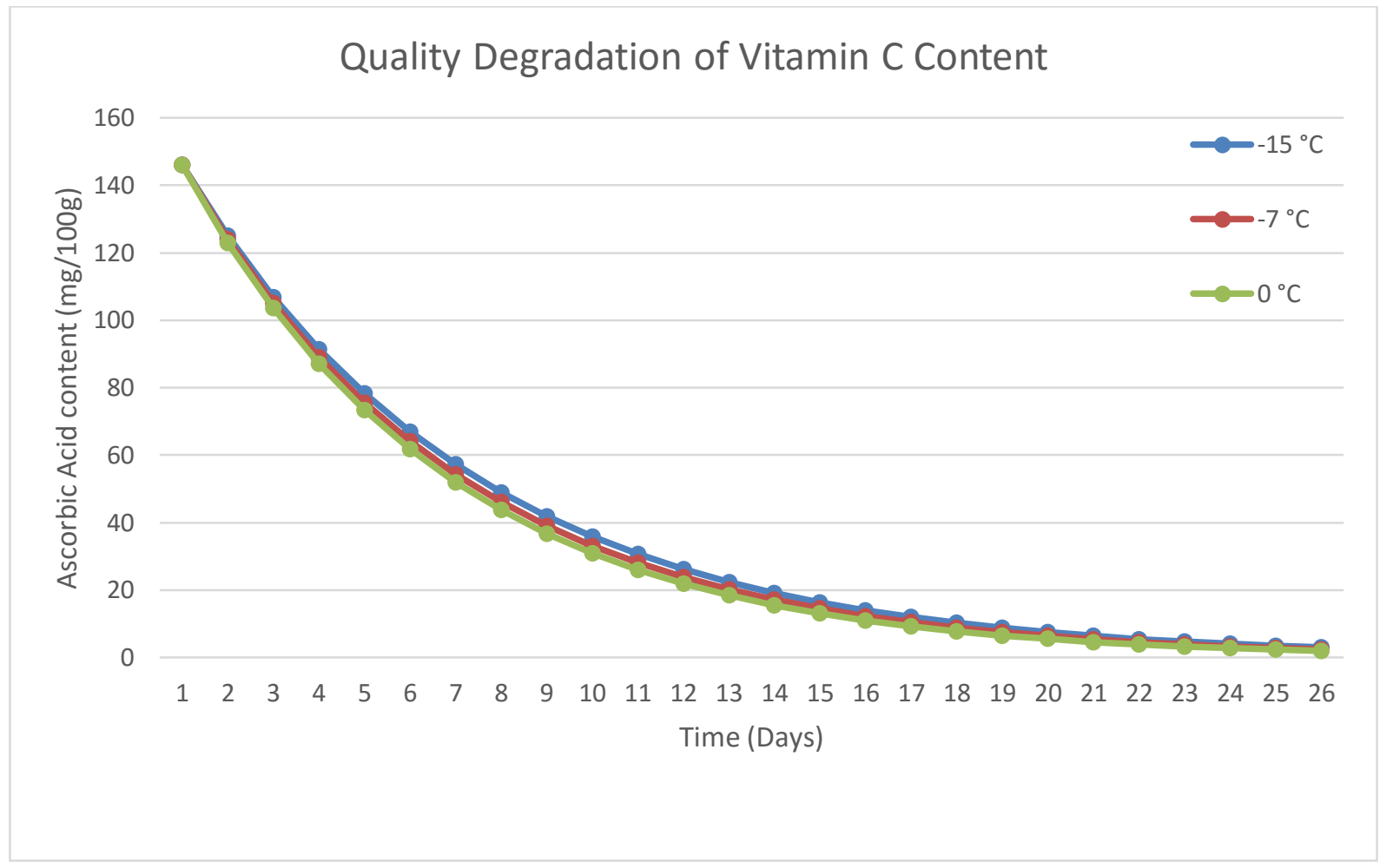

Figure 5: A) The quality degradation of starch content has been given in three temperatures of $15^{\circ} \mathrm{C},-7^{\circ} \mathrm{C}$ and $0^{\circ} \mathrm{C}$.

B) The quality degradation of vitamin $\mathrm{C}$ content has been given in three temperatures of $-15^{\circ} \mathrm{C},-7^{\circ} \mathrm{C}$ and $0^{\circ} \mathrm{C}$.

As it can be seen in figures 4 and 5 , the quality aspects follow very similar trends with respect to the temperatures they are placed, with the exception of Starch which has a slightly bigger difference when placed in different temperatures. In order to combine these aspects into one we have used the GSI (Global Stability Index) method in order to give each weight a different level of importance and follow their quality trends. To get a better view of the GSI with different weights, four different scenarios have been put into place. Scenario 1, where all the quality levels have been given similar weights (gamma=[0.33 0.330 .33 ), Scenario 2, where a greater weight has been given to Vitamin C (gamma=[0.5 0.250 .25$]$ ), scenario 3, where a greater weight has 
been given to sugar (gamma=[0.25 0.50 .25$]$ ) and scenario 4 , where a greater weight has been given to starch (gamma=[0.25 0.25 0.5]). This can be seen in figure 6 .

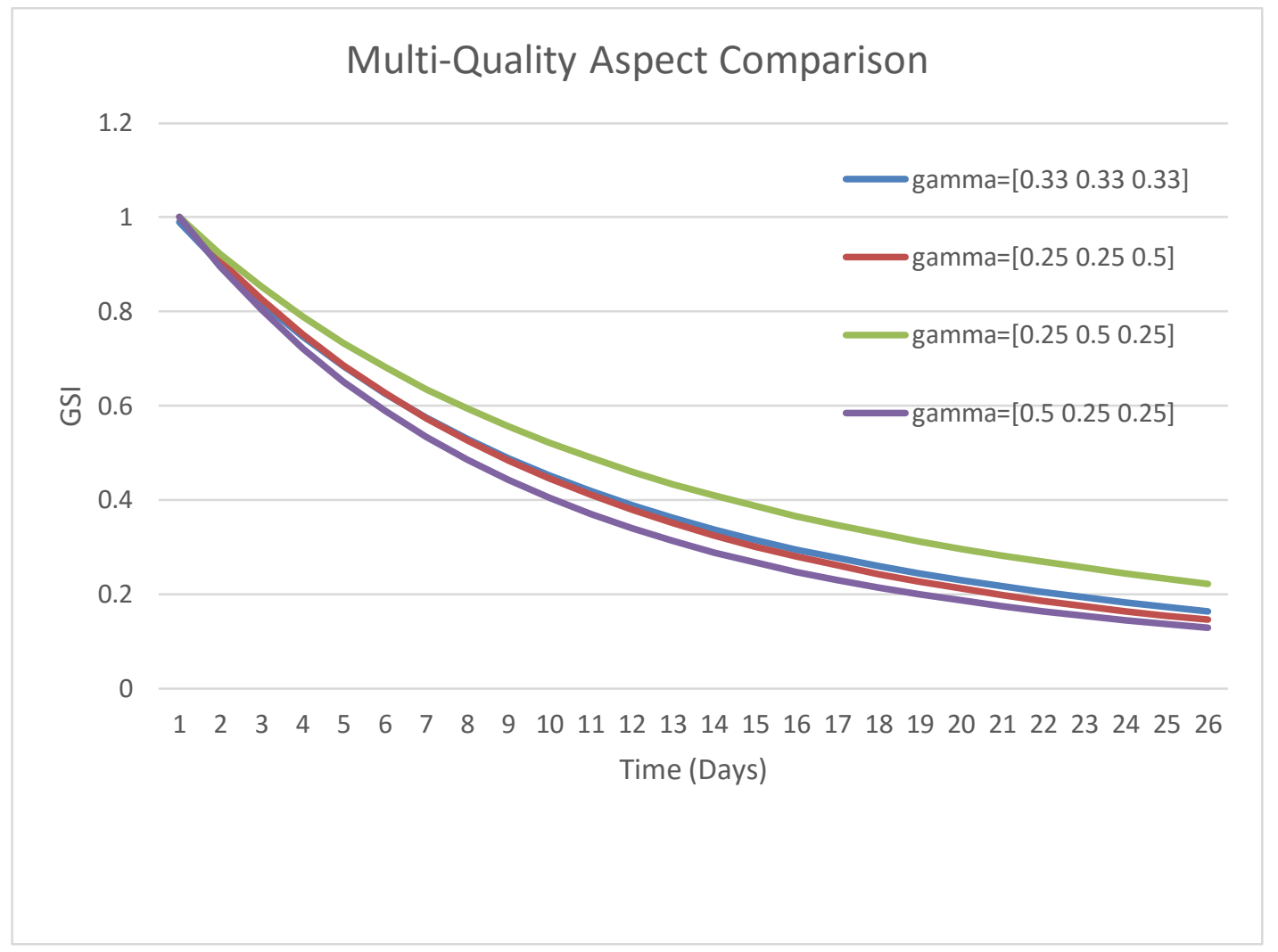

Figure 6: Multi-quality aspect comparison by giving different weights to the three aspects. This figure illustrates the four different scenarios which have been put into place in order to show the impact of weights on different aspects.

For simplicity, the calculations for five scenarios have been put in place to compare with the three variables of: $n, Q_{r}$ and $r$. For all scenarios it was noticed that the optimal $r$ was around 90. The five scenarios are as follows:

Scenario 1: $n=1-50, r=1-100 \rightarrow$ optimal solution: $n=1, Q_{r}=18, r$

$$
=90, \text { TotalCost }=\$ 2353.89
$$


Scenario 2: $n=50-100, r=1-100 \rightarrow$ optimal solution: $n=50, Q_{r}=7, r$

$$
=90, \text { TotalCost }=\$ 5445.22
$$

Scenario 3: $n=100-150, r=1-100 \rightarrow$ optimal solution: $n=100, Q_{r}=16, r$

$$
=90, \text { TotalCost }=\$ 5832.92
$$

Scenario $4: n=150-200, r=1-100 \rightarrow$ optimal solution: $n=150, Q_{r}=18, r$

$$
=90, \text { TotalCost }=\$ 5948.78
$$

Scenario 5: $n=200-250, r=1-100 \rightarrow$ optimal solution: $n=200, Q_{r}=17, r$

$$
=90, \text { TotalCost }=\$ 6030.09
$$

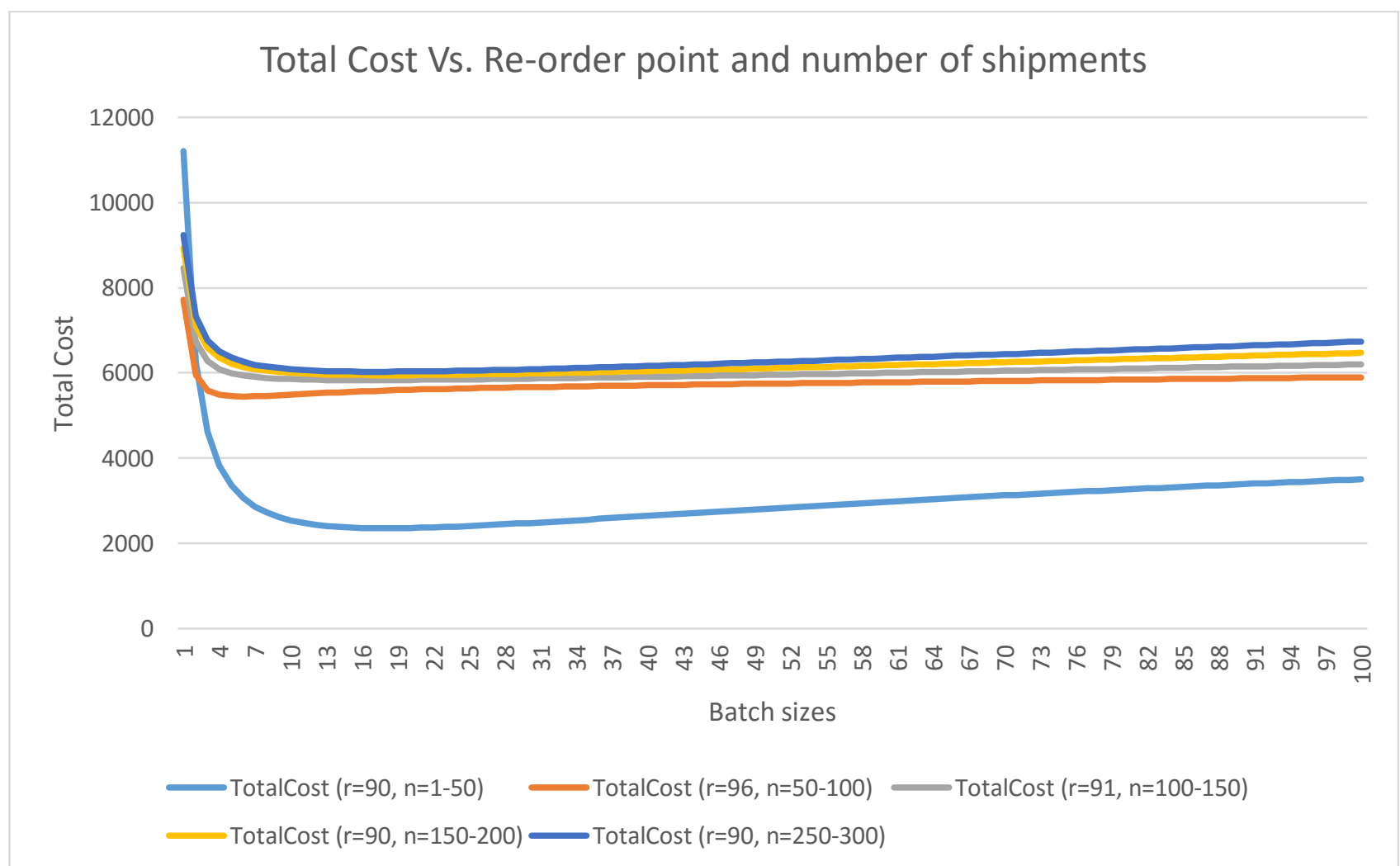

Figure 7: Total Cost of the supply chain with respect to different number of shipments and reorder points has been illustrated in this graph. Also the $\mathrm{X}$-axis represents the batch sizes. 
Clearly it can be noticed that the optimal number of shipments for $n$ is equal to the lowest amount in the interval. The higher the value of $n$, the greater the total costs for the supply chain shall become. But because of the constraints that should be put on $n$, this equation should be solved using a Genetic Algorithm to get the most feasible results. For all scenarios it can be noticed that the re-order point has an optimal value and can be calculated by differentiating Equation (15).

\section{Conclusions:}

A study on the cold supply chain of green beans had been put in place in this paper in which we took a look at the entire process from where the products are picked, to the warehouse they are put in, the transportation costs and also the costs endured during their period in the retailer. All temperatures have been incorporated in this paper with respect to different quality levels. We took a look at different aspects of quality such as Starch (aesthetics), Sugar (taste) and Vitamin C (minerals). We noticed that the lower the amount of shipments the better for our product as it reduces the quality degradation and the total costs of the chain. We also investigated the impact of different aspects in terms of quality degradation and it can be clearly seen the different impacts that these three aspects have and managers can base their quality criteria by giving each aspect different weights to be able to control the overall quality criteria of their products.

There are numerous methods that can be taken to further improve this research such as creating a multi warehouse and multi retailer combination and investigate the costs in a more realistic fashion. Also we can add uncertainty in the demand of the products from the retailer. 


\section{References}

Achour, Mohsen. "A new method to assess the quality degradation of food products during storage." Journal of Food Engineering 75.4 (2006): 560-564.

Arrhenius, Svante. "On the reaction velocity of the inversion of cane sugar by acids." J. Phys.

Chem 4 (1889): 226.

Blackburn, Joseph, and Gary Scudder. "Supply chain strategies for perishable products: the case of fresh produce." Production and Operations Management 18.2 (2009): 129-137.

Bogataj, Marija, Ludvik Bogataj, and Robert Vodopivec. "Stability of perishable goods in cold logistic chains." International Journal of Production Economics 93 (2005): 345-356.

Cai, Xiaoqiang, et al. "Optimization and coordination of fresh product supply chains with freshness-keeping effort." Production and Operations Management 19.3 (2010): 261-278.

Chopra, Sunil, and P. Meindl. "Supplier Chain Management-Strategies, Planning, and Operation." (2001): 22-23.

Clark, Kim B., and Takahiro Fujimoto. "Lead time in automobile product development explaining the Japanese advantage." Journal of Engineering and Technology Management 6.1 (1989): 25-58. 
Cooper, Martha C., and Lisa M. Ellram. "Characteristics of supply chain management and the implications for purchasing and logistics strategy." The International Journal of Logistics Management 4.2 (1993): 13-24.

Covert, Richard P., and George C. Philip. "An EOQ model for items with Weibull distribution deterioration." AIIE transactions 5.4 (1973): 323-326.

Das, Chandrasekhar. "Effect of lead time on inventory: a static analysis."Operational Research Quarterly (1975): 273-282.

Fujiwara, Okitsugu, and U. L. J. S. R. Perera. "EOQ models for continuously deteriorating products using linear and exponential penalty costs." European Journal of Operational Research 70.1 (1993): 104-114.

Ghare, P. M., and G. F. Schrader. "A model for exponentially decaying inventory." Journal of industrial Engineering 14.5 (1963): 238-243.

Giannakourou, M. C., and P. S. Taoukis. "Kinetic modelling of vitamin C loss in frozen green vegetables under variable storage conditions." Food Chemistry 83.1 (2003): 33-41.

Giannakourou, M. C., and P. S. Taoukis. "Kinetic modelling of vitamin C loss in frozen green vegetables under variable storage conditions." Food Chemistry 83.1 (2003): 33-41.

Kaplan, Robert S. "A dynamic inventory model with stochastic lead times."Management Science 16.7 (1970): 491-507.

Kuo, Ju-Chia, and Mu-Chen Chen. "Developing an advanced multi-temperature joint distribution system for the food cold chain." Food Control21.4 (2010): 559-566. 
Liao, Ching-Jong, and Chih-Hsiung Shyu. "An analytical determination of lead time with normal demand." International Journal of Operations \& Production Management 11.9 (1991): $72-78$.

Martins, R. C., and C. L. M. Silva. "Colour and chlorophyll's degradation kinetics of frozen green beans (Phaseolus Vulgaris, L.)." (2000).

Martins, R. C., and C. L. M. Silva. "Kinetics of frozen stored green bean (Phaseolus vulgaris L.) quality changes: Texture, vitamin C, reducing sugars, and starch." Journal of food science 68.7 (2003): 2232-2237.

Nahmias, Steven. "Perishable inventory theory: A review." Operations research 30.4 (1982): 680708.

Ouyang, Liang-Yuh, and Bor-Ren Chuang. "Mixture inventory model involving variable lead time and controllable backorder rate." Computers \& industrial engineering 40.4 (2001): 339-348.

Sajadieh, Mohsen S., Mohammad R. Akbari Jokar, and Mohammad Modarres. "Developing a coordinated vendor-buyer model in two-stage supply chains with stochastic leadtimes." Computers \& Operations Research 36.8 (2009): 2484-2489.

Sexton, Richard J., Mingxia Zhang, and James Chalfant. Grocery retailer behavior in the procurement and sale of perishable fresh produce commodities. USDA Economic Research Sevice, 2003.

Shah, Y. K., and M. C. Jaiswal. "An order-level inventory model for a system with constant rate of deterioration." Opsearch 14.3 (1977): 174-184. 
Tadikamalla, Pandu R. "An EOQ inventory model for items with gamma distributed deterioration." AIIE transactions 10.1 (1978): 100-103.

Tang, Ou, and Robert W. Grubbström. "Considering stochastic lead times in a manufacturing/remanufacturing system with deterministic demands and returns." International Journal of Production Economics 93 (2005): 285-300.

Weiss, Howard J. "Economic order quantity models with nonlinear holding costs." European Journal of Operational Research 9.1 (1982): 56-60.

Zanoni, Simone, and Lucio Zavanella. "Chilled or frozen? Decision strategies for sustainable food supply chains." International Journal of Production Economics 140.2 (2012): 731-736.

\section{Glossary}

D demand rate

$\boldsymbol{P} \quad$ picking rate

$\boldsymbol{Q}_{\boldsymbol{w}}$ replenishment quantity at warehouse

$\boldsymbol{Q}_{\boldsymbol{r}} \quad$ replenishment quantity at retailer

$\boldsymbol{r} \quad$ re - order point for buyer (retailer)

$\boldsymbol{A}_{\boldsymbol{w}} \quad$ setup cost for warehouse

$\boldsymbol{A}_{\boldsymbol{b}} \quad$ setup cost for buyer 
$\boldsymbol{E}$ energy consumption required to cool a unit of food per unit time to a given temperature $\left(\frac{\mathrm{kWh}}{\mathrm{kg}}\right)$

C cost of cooling energy $\left[\frac{\$}{\mathrm{kWh}}\right]$

$\boldsymbol{h}_{\boldsymbol{w}} \quad$ inventory cooling costs at warehouse per unit

$\boldsymbol{\beta}_{\boldsymbol{w}}$ fixed inventory holding costs at warehouse per unit

$\boldsymbol{h}_{\boldsymbol{b}} \quad$ inventory cooling cost at buyer per unit

$\boldsymbol{h}_{\boldsymbol{r}} \quad$ fixed inventory holding costs at buyer per unit

$\pi \quad$ shortage cost for buyer per unit time

l lead time from vendor to retailer

$\boldsymbol{q}_{\boldsymbol{i 0}} \quad$ initial quality of aspect i

$\boldsymbol{q}_{\boldsymbol{i}} \quad$ momentary quality of aspect i

$\boldsymbol{q}_{\text {ieq }}$ equilibrium quality of aspect i

$\boldsymbol{t}_{\mathbf{1}}$ amount of time consumed for picking products from field

$\boldsymbol{t}_{2}$ constant lead time from field to producers storage room (harvesting lead time)

$t_{3}$ amount of time each unit spends on average in the storage room

$\boldsymbol{t}_{4}$ stochastic lead time from storage room to retailer $\mathrm{f}(\mathrm{l})=\lambda \mathrm{e}^{-\lambda \mathrm{l}}$

$\boldsymbol{t}_{\mathbf{5}}$ average amount of time each unit spends on retailer shelf

$n \quad$ number of shipments 
$\boldsymbol{V} \quad$ initial value of each unit

$\boldsymbol{\alpha}_{\boldsymbol{i}}\left(\boldsymbol{T}_{\boldsymbol{j}}\right)$ rate of degradation i at temperature $\mathrm{T}_{\mathrm{j}}$

$\boldsymbol{T}_{\text {ref }}$ reference temperature

$\boldsymbol{k}_{\boldsymbol{r} \boldsymbol{e f}}$ reaction rate for quality aspect i, at reference temperature

$\boldsymbol{k}_{\boldsymbol{i}} \quad$ temperature dependent reaction rate for quality aspect i

$\boldsymbol{E}_{\boldsymbol{A}} \quad$ Acitvation energy

$\boldsymbol{R} \quad$ universal gas constant

$\gamma_{i} \quad$ weighting factor for quality aspect i 